\title{
ASTHMA
}

\section{Individualised homeopathy as an adjunct in the treatment of childhood asthma: a randomised placebo controlled trial}

\author{
A White, P Slade, C Hunt, A Hart, E Ernst
}

Thorax 2003;58:317-32

See end of article for authors' affiliations

Correspondence to Dr A White, Department of Complementary Medicine, Peninsula Medical School,

25 Victoria Park Road

Exeter EX2 4NT UK;

adrian.white@pms.ac.uk

Revised version received 30 October 2002

Accepted for publication 23 November 2002
Background: Homeopathy is frequently used to treat asthma in children. In the common classical form of homeopathy, prescriptions are individualised for each patient. There has been no rigorous investigation into this form of treatment for asthma.

Methods: In a randomised, double blind, placebo controlled trial the effects of individualised homeopathic remedies were compared with placebo medication in 96 children with mild to moderate asthma as an adjunct to conventional treatment. The main outcome measure was the active quality of living subscale of the Childhood Asthma Questionnaire administered at baseline and follow up at 12 months. Other outcome measures included other subscales of the same questionnaire, peak flow rates, use of medication, symptom scores, days off school, asthma events, global assessment of change, and adverse reactions.

Results: There were no clinically relevant or statistically significant changes in the active quality of life score. Other subscales, notably those measuring severity, indicated relative improvements but the sizes of the effects were small. There were no differences between the groups for other measures.

Conclusions: This study provides no evidence that adjunctive homeopathic remedies, as prescribed by experienced homeopathic practitioners, are superior to placebo in improving the quality of life of children with mild to moderate asthma in addition to conventional treatment in primary care.
$\mathrm{H}$ omeopathic treatment involves selecting a treatment according to the precise symptoms of each individual patient. Homeopathic remedies are prepared by serial dilution, often to the extent that none of the original substance remains. Suggested mechanisms include the notion that the activity of the remedy is held by the "memory" of water. ${ }^{1}$

Homeopathy is frequently used in the UK to treat asthma in children. In one survey of children with asthma $15 \%$ of the respondents had used homeopathy. ${ }^{2}$ However, there is no clear evidence that it is superior to placebo. A systematic review ${ }^{3}$ located only three randomised controlled trials, ${ }^{4-6}$ two of which reported some positive effects. None of these was a true test of individualised homeopathy. A wider systematic review of the effectiveness of homeopathy for all conditions reached a positive conclusion.

We have undertaken a multicentre study to determine whether homeopathic remedies, prescribed according to the practice of individualised classical homeopathy and given in addition to conventional medicine, are superior to placebo in the treatment of children with asthma.

\section{METHODS}

In a randomised, double blind, placebo controlled trial the effects of individualised homeopathic remedies given in normal homeopathic practice were compared with placebo medication in children with mild to moderate asthma. The study took place in five general practices in market towns in Somerset, UK and ethical approval for the study was granted by the West Somerset ethics committee.

All children aged 5-15 years were identified from practice records if a diagnosis of asthma was recorded and a prescription for a $\beta$ agonist and/or corticosteroid inhaler had been issued within the previous 3 months. Their parents were sent a letter inviting participation in the study. Children who had been prescribed oral corticosteroids for acute asthma within the previous 12 months were excluded for reasons of safety. Children who had previously consulted a homeopath for any condition and received a homeopathic prescription were excluded, as were children who were unable to complete the necessary forms or were thought by their doctor to be unlikely to comply with instructions.

After obtaining written informed consent, demographic data, medical history and severity of asthma (use of inhalers, days off school) during the previous month were recorded. The appropriate Childhood Asthma Questionnaire (CAQ) for the age of the child was administered (see below). Peak expiratory flow rate (PEFR) was measured and the best of three attempts recorded. The medical history was verified against surgery records.

Individualised homeopathy was provided by three nonmedically trained classical homeopaths, each of whom had been in practice for at least 10 years and met membership criteria for the Society for Homeopaths, UK. Patients could attend up to six homeopathic consultations over the course of a year, plus extra telephone consultations as necessary according to normal practice. Other advice such as dietary recommendations could be given in the usual way. Children were encouraged not to alter their conventional medication without advice from their asthma nurse or doctor. There was no maximum number of prescriptions allowed for each subject. In order to ensure a reasonable degree of uniformity of practice, the three homeopaths held case conferences at approximately monthly intervals. Each child's case was presented and discussed on at least one occasion. The homeopaths reported that their approaches were substantially the same and that any differences would be unlikely to affect the outcome.

Children were classified for the purposes of this study as mild or moderate according to whether they reported using prophylactic asthma medication more or less than half the 
time in the previous 3 months. Patients were randomly allocated to two groups after stratification by severity and by centre. All patients, homeopaths, and research staff remained blind to the randomisation and the code was not broken until the data had been analysed. Blinding was achieved in the following manner. All prescriptions were faxed to a London based homeopathic pharmacist and dispensed in two forms with identical appearance-genuine homeopathic preparation prepared in the standard manner or placebo, consistently labelled A and B. Both preparations were sent to a solicitor's office where the clerk consulted randomisation lists (prepared in advance by personnel not involved in the study using computer generated random numbers in blocks of four) and selected the designated package (A or B). The homeopathic pharmacist informed only a hospital pharmacist in Royal Devon and Exeter Hospitals whether A or B was the genuine remedy. This neutral pharmacist also received faxed copies of the randomisation lists from the solicitor at regular intervals in order to make information on group allocation available locally in case of an emergency, but this was not required. Considering the rigorous method of blinding used in this study, it was not considered necessary to test its success. Data were entered into Excel spreadsheets by the research nurses and principal investigator.

\section{Outcome measures}

A measure of asthma quality of life was chosen as the primary outcome measure in accordance with current trends and at the recommendation of a reviewer appointed by the funding body. The Childhood Asthma Questionnaire (CAQ) comprises three versions (CAQA, CAQB, CAQC) for children aged 4-7, $8-11$, and $12-16$ years, respectively, and has been validated..$^{8-10}$ The questionnaires contain between 14 and 31 questions for children to answer, and six questions for parents in the two younger age groups. The CAQA has three subscales and the CAQB and CAQC have five subscales, but no subscale comprises the same set of questions in all three questionnaires. We chose the (active) quality of living subscale as the primary outcome measure as suggested by the author (French, personal communication). It assesses how children feel during their daily activities such as playing, running and swimming using reasonably similar questions for all three age groups. Initial experience with this measure suggests that changes of 2-3 points on the original scales are clinically meaningful. ${ }^{10}$ In order to combine the scores for different age groups in the analysis, scales were standardised to 100 and pooled. A clinically relevant difference was considered to be an improvement of seven points on this combined scale. Severity was chosen as the supporting measure and assessed symptoms such as wheezing, coughing, and waking at night. For children aged 4-7 years these symptoms were assessed only by the parent/guardian. All remaining subscales were secondary outcome measures.

The CAQs were completed at baseline and at the end of the study ( 52 weeks). The long duration of the study was chosen to allow time for the fundamental changes which homeopathic medication is claimed to initiate. However, more rapid changes (including aggravation of symptoms) are also relevant and therefore earlier time points were also used.

Other measures included a weekly diary based on one previously described ${ }^{11}$ to record the number of days in the previous week on which the child had been out of breath while running, while sitting still, wheezing in daytime, coughing in daytime, wheezing at night, coughing at night, and required extra doses of inhaler. In addition the diary recorded the number of days the child had to miss school (or stay in the house) because of asthma, and asthma "events" - for example, extra appointments to see own doctor, a course of antibiotics or steroids, or hospital visit due to asthma. ${ }^{12}$ This diary was administered for the first 12 weeks and the last 4 weeks of
Table 1 Baseline data of children with asthma randomised to homeopathic or placebo groups

\begin{tabular}{lll}
\hline & $\begin{array}{l}\text { Homeopathy } \\
\text { group }(\mathrm{n}=46)\end{array}$ & $\begin{array}{l}\text { Placebo group } \\
(\mathrm{n}=47)\end{array}$ \\
\hline Male & $27(59)$ & $23(49)$ \\
Mild severity & $13(28)$ & $15(32)$ \\
Eczema & $15(33)$ & $17(36)$ \\
Hay fever & $26(57)$ & $21(45)$ \\
Smoker in household & $18(39)$ & $16(34)$ \\
Exercise induced asthma & $6(13)$ & $5(11)$ \\
Prescribed inhaled steroids & $33(72)$ & $36(77)$ \\
Mean (SD) height (cm) & $140.6(17.1)$ & $144.3(18.5)$ \\
Mean (SD) weight (kg) & $38.1(14.7)$ & $42.3(15.5)$ \\
Mean (SD) PEFR (\% predicted) & $100.4(17.0)$ & $96.9(15.8)$ \\
$\begin{array}{l}\text { Mean (SD) duration of asthma } \\
\text { (years) }\end{array}$ & $4.2(2.8)$ & $4.8(3.2)$ \\
$\begin{array}{l}\text { Median (range) number of } \\
\text { prescriptions in previous 3 }\end{array}$ & $2(0-8)$ & $2(0-6)$ \\
months & & $1(0-3)$ \\
$\begin{array}{l}\text { Median (range) number of } \\
\text { recorded asthma events in } \\
\text { previous 12 months }\end{array}$ & $0(0-3)$ & \\
\hline
\end{tabular}

Values are numbers (\%) in each subgroup unless stated otherwise PEFR = peak expiratory flow rate.

the study period. For the intervening period monthly diaries were completed for days missed from school and asthma events. Patients were also asked whether they had experienced any possible adverse events because "aggravations" are believed to indicate a response to homeopathy.

At the final evaluation patients and their parent or guardian were asked to rate the change in asthma severity in five categories from very much better/cured to very much worse. Peak expiratory flow rate (PEFR) was measured by the research nurse at baseline and at 4,8 , and 12 weeks.

In estimating the sample size, one available study ${ }^{6}$ with 28 adults with asthma showed a significant difference between the effect of a form of homeopathy and placebo using subjective assessment of symptom severity by visual analogue scale (VAS). We considered that a total sample size of 100 would be both adequate and feasible. A post hoc power calculation showed that a study with 42 children per group would have $80 \%$ power to detect a moderate effect size $(0.5)$ at the $5 \%$ level, given that the correlation between baseline values and those following treatment for the pooled standardised quality of life measure was 0.68 .

\section{Statistical analysis}

The analysis included all children who completed the baseline CAQ. Missing questionnaires were dealt with by carrying forward the baseline value-that is, "no change". Where only isolated values were missing from a questionnaire, a value was imputed based on the average of the related items present. Changes in quality of life scores were analysed using analysis of covariance, including baseline scores and the baseline severity group. For each of the active quality of life scores and the severity score the data from the three age groups were pooled by converting scores into standardised values using the formula (score recorded - minimum possible) $\times 100 /$ (maximum possible - minimum possible). Analysis was carried out in Minitab version 10.51 and was by intention to treat. Possible clustering effects due to centres were investigated by adding a random factor in Proc mixed using SAS version 6.12. The time until an asthma event or the times between events were analysed by the Wilcoxon test using strata for the baseline severity with the STS test procedure in Intercooled Stata version 6.0.

\section{RESULTS}

Ninety three children were recruited and randomised between October 1997 and March 1999, all of whom used $\beta$ adrenergic 


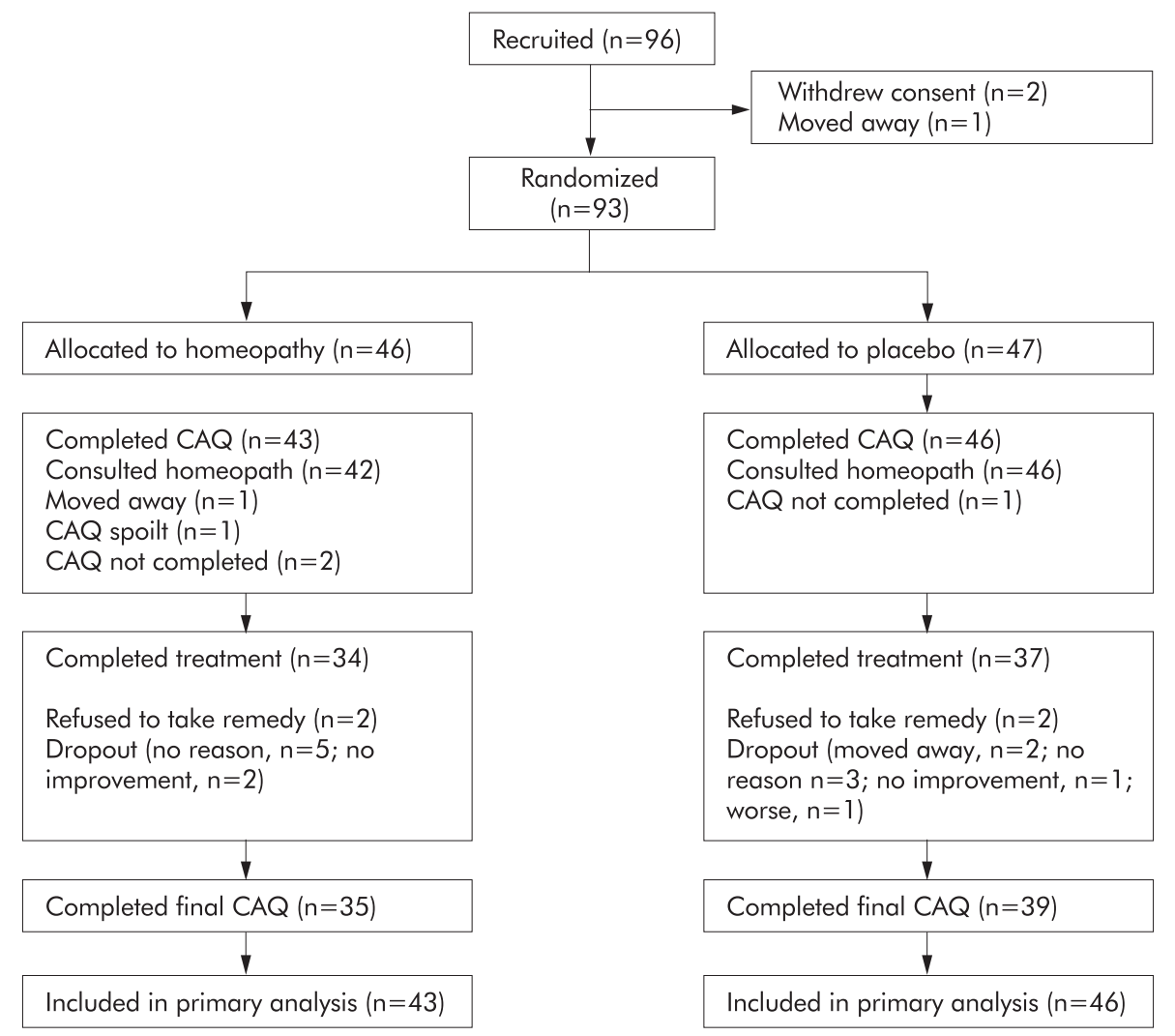

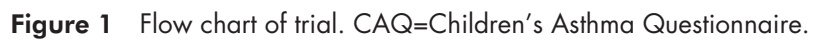

inhalers (table 1). Eight used sodium cromoglycate inhalers (six in homeopathy group, two in placebo group) and one child in the homeopathy group also used salbutamol nebules. The overall mean (SD) number of homeopathy sessions attended was 5.5 (1.3).

Seventy four children completed both sets of questionnaires for the CAQ scores (fig 1). A further 15 completed the first questionnaire and were included in the intention to treat analysis (with a change of zero imputed). Seven completed neither questionnaire. Of these seven there were baseline data for six, of whom three were randomised. Table 1 gives summary baseline demographic and clinical characteristics for the two groups. There were no apparent differences between the two groups at baseline, or between the characteristics of children who stayed in the study and those who dropped out (data not shown). In addition, there were no relevant differences in other medications prescribed, hospital outpatient attendances or admissions, or other significant illnesses. Because of missing data, the number of children in the various analyses was not the same.

\section{Primary outcome measure: active quality of life score}

There was no clear evidence of a statistically significant treatment effect in the active quality of life score (table 2). Furthermore, this result was not meaningfully different in a per protocol analysis. For the analysis of covariance on the pooled scores a 95\% confidence interval for the treatment effect was -3.98 to 6.62 points. The results were similar when centre effects were included.

\section{Secondary outcome measures}

Table 3 shows summary statistics for the changes in the other CAQ scores. Although for each of the subscales the treatment effect indicated a relative improvement in scores, those which

\begin{tabular}{|c|c|c|c|c|c|c|}
\hline Age group & $\begin{array}{l}\text { Possible scores } \\
\text { (min-max) }\end{array}$ & Group & $\begin{array}{l}\text { Mean (SD) baseline } \\
\text { score }\end{array}$ & $\begin{array}{l}\text { Mean change in } \\
\text { score }\end{array}$ & $\begin{array}{l}\text { Estimate of treatment } \\
\text { effect from ANCOVA } \\
(95 \% \mathrm{CI})\end{array}$ & $\mathrm{p}$ value (ANCOVA) \\
\hline A: $4-7$ years & $10-40$ & $\begin{array}{l}\text { Hom }(n=8) \\
\text { Plac }(n=7)\end{array}$ & $\begin{array}{l}34.80(1.8) \\
35.66(3.3)\end{array}$ & $\begin{array}{l}0.00 \\
0.94\end{array}$ & $\begin{array}{l}-0.30 \\
(-3.55 \text { to } 2.94)\end{array}$ & 0.84 \\
\hline B: 8-11 years & $7-35$ & $\begin{array}{l}\text { Hom }(n=20) \\
\text { Plac }(n=19)\end{array}$ & $\begin{array}{l}28.27(3.8) \\
27.95(3.6)\end{array}$ & $\begin{array}{l}0.85 \\
-0.11\end{array}$ & $\begin{array}{l}1.02 \\
(-1.27 \text { to } 3.32)\end{array}$ & 0.37 \\
\hline C: $12-16$ years & $8-36$ & $\begin{array}{l}\text { Hom }(n=15) \\
\text { Plac }(n=20)\end{array}$ & $\begin{array}{l}28.93(3.1) \\
29.80(3.9)\end{array}$ & $\begin{array}{l}0.20 \\
-0.15\end{array}$ & $\begin{array}{l}0.08 \\
(-1.95 \text { to } 2.12)\end{array}$ & 0.93 \\
\hline $\begin{array}{l}\text { Pooled standardised } \\
\text { score }\end{array}$ & $0-100$ & $\begin{array}{l}\text { Hom }(n=43) \\
\text { Plac }(n=46)\end{array}$ & $\begin{array}{l}76.79(11.9) \\
77.77(13.3)\end{array}$ & $\begin{array}{l}1.66 \\
0.09\end{array}$ & $\begin{array}{l}1.32 \\
(-3.98 \text { to } 6.62)\end{array}$ & 0.59 \\
\hline
\end{tabular}

Higher score indicates better quality of life. 
Table 3 Changes from baseline to 12 months in other subscales of Childhood Asthma Questionnaire in homeopathy (Hom) and placebo (Plac) groups

\begin{tabular}{|c|c|c|c|c|c|c|}
\hline Age group & Subscale & $\begin{array}{l}\text { Possible scores } \\
\text { (min-max) }\end{array}$ & Group & $\begin{array}{l}\text { Mean baseline } \\
\text { score }\end{array}$ & $\begin{array}{l}\text { Mean change in } \\
\text { score }\end{array}$ & $\begin{array}{l}\text { Unadjusted estimate of } \\
\text { treatment effect }\end{array}$ \\
\hline \multirow[t]{2}{*}{ A: $4-7$ years } & Distress* & $4-15$ & $\begin{array}{l}\text { Hom }(n=8) \\
\text { Plac }(n=7)\end{array}$ & $\begin{array}{l}11.69 \\
10.14\end{array}$ & $\begin{array}{l}-1.63 \\
-0.64\end{array}$ & -0.99 \\
\hline & $\begin{array}{l}\text { Severity (assessed } \\
\text { by parents) }\end{array}$ & $5-19$ & $\begin{array}{l}\text { Hom }(n=8) \\
\text { Plac }(n=7)\end{array}$ & $\begin{array}{l}9.00 \\
7.29\end{array}$ & $\begin{array}{l}-3.50 \\
-1.14\end{array}$ & -2.36 \\
\hline \multirow[t]{4}{*}{ B: 8-11 years } & Distress & $6-30$ & $\begin{array}{l}\text { Hom }(n=20) \\
\text { Plac }(n=19)\end{array}$ & $\begin{array}{l}23.95 \\
25.00\end{array}$ & $\begin{array}{l}-0.57 \\
-0.06\end{array}$ & -0.51 \\
\hline & $\begin{array}{l}\text { Passive quality } \\
\text { of livingt }\end{array}$ & $4-20$ & $\begin{array}{l}\text { Hom }(n=20) \\
\text { Plac }(n=19)\end{array}$ & $\begin{array}{l}16.95 \\
17.37\end{array}$ & $\begin{array}{l}0.85 \\
-0.37\end{array}$ & 1.22 \\
\hline & Severity (by child) & $6-23$ & $\begin{array}{l}\text { Hom }(n=20) \\
\text { Plac }(n=19)\end{array}$ & $\begin{array}{l}11.85 \\
10.95\end{array}$ & $\begin{array}{l}-2.60 \\
-1.21\end{array}$ & -1.39 \\
\hline & $\begin{array}{l}\text { Severity (assessed } \\
\text { by parents) }\end{array}$ & $5-19$ & $\begin{array}{l}\text { Hom }(n=20) \\
\text { Plac }(n=19)\end{array}$ & $\begin{array}{l}7.35 \\
7.32\end{array}$ & $\begin{array}{l}-1.30 \\
-0.68\end{array}$ & -0.62 \\
\hline \multirow[t]{4}{*}{ C: $12-16$ years } & Distress & $12-60$ & $\begin{array}{l}\text { Hom }(n=15) \\
\text { Plac }(n=20)\end{array}$ & $\begin{array}{l}26.03 \\
26.45\end{array}$ & $\begin{array}{l}-1.50 \\
1.69\end{array}$ & -3.19 \\
\hline & $\begin{array}{l}\text { Teenage quality } \\
\text { of living } t\end{array}$ & $5-23$ & $\begin{array}{l}\text { Hom }(n=15) \\
\text { Plac }(n=20)\end{array}$ & $\begin{array}{l}16.87 \\
17.90\end{array}$ & $\begin{array}{l}0.87 \\
-0.50\end{array}$ & 1.37 \\
\hline & Severity & $9-34$ & $\begin{array}{l}\text { Hom }(n=15) \\
\text { Plac }(n=20)\end{array}$ & $\begin{array}{l}19.07 \\
18.25\end{array}$ & $\begin{array}{l}-3.27 \\
-1.70\end{array}$ & -1.57 \\
\hline & Reactivity & $5-24$ & $\begin{array}{l}\text { Hom }(n=15) \\
\text { Plac }(n=20)\end{array}$ & $\begin{array}{l}11.40 \\
10.80\end{array}$ & $\begin{array}{l}1.13 \\
1.40\end{array}$ & -0.27 \\
\hline
\end{tabular}

*These data are unreliable as there were a large number of missing values in the questionnaires.

†Reduction in scores indicates improvement except for quality of living in which increase in score indicates improvement.

showed any changes of possible clinical relevance are only on the severity subscales (table 3 ). This subscale was investigated further post hoc by constructing a pooled standardised score using the parents' assessment for children in group A, and the children's assessments for groups B and C. There is clear evidence of a general reduction (improvement) in the scores, but the apparent differential treatment effect size is small. An analysis of covariance, taking into account baseline scores and initial severity group (mild or moderate), yielded an estimate of -8.0 for the treatment effect ( $95 \% \mathrm{CI}-13.7$ to $-2.2, \mathrm{p}=0.01$ ). Similar results were obtained when centre effects were included. There were no differences between the groups for the other outcomes listed in table 4, for global improvement, symptom scores, or asthma events (data not shown).

\section{Adverse events}

In the homeopathy group 13 events were reported in 12 children as follows: exacerbations of eczema (4) and of asthma (3); headache (3); fever (1); sickness (1); and no details (1). Six of these events were reported after the first remedy had been taken. In the placebo group 10 events were reported in eight children as follows: exacerbations of eczema (2) and asthma (2); rash (1); depression or irritability (3), sleeping difficulties (2). One child in whom cough, behaviour problems, and sleeping difficulties were reported persistently was withdrawn from the study. Five events were reported after the first remedy.

Table 4 Other outcome measures

\begin{tabular}{llll}
\hline Measure & Change & $\begin{array}{l}\text { Homeopathy } \\
\text { group }(\mathrm{n}=43)\end{array}$ & $\begin{array}{l}\text { Placebo group } \\
(\mathrm{n}=46)\end{array}$ \\
\hline Improvement in & $<15 \%$ & $31(72)$ & $29(63)$ \\
PEFR* $^{*}$ & $\geqslant 15 \%$ & $12(28)$ & $17(37)$ \\
Use of inhalers* & Increased & $1(2)$ & $1(2)$ \\
& No change & $24(56)$ & $27(59)$ \\
& Reduced & $18(42)$ & $18(39)$ \\
Days off school in & Increased & $2(5)$ & $4(9)$ \\
past month* & No change & $32(74)$ & $32(70)$ \\
& Reduced & $9(21)$ & $10(21)$ \\
\hline
\end{tabular}

*Baseline compared with end of study; missing values assumed "no change".

Values are numbers $(\%)$

\section{DISCUSSION}

This randomised patient, practitioner and observer blinded clinical trial of classical individualised homeopathy found no evidence that homeopathic remedies were superior to placebo in improving the quality of life of children with mild to moderate asthma as an adjunct to normal treatment in primary care. There was no evidence of a clinically relevant change in quality of life score, as even the extreme values of the confidence interval ( -3.98 to 6.62 ) would not be described as clinically relevant (7-point) improvement on the standardised scale. For the severity subscale the pooled standardised score revealed an effect, but the estimate would not be clinically relevant. Moreover, it is not clear that the severity subscales for different age groups were measuring exactly the same characteristic.

There were no changes in any of the other measures including the rate of exacerbations, which is believed by homeopaths to be a hallmark of successful treatment. ${ }^{13}$ A post hoc survival analysis suggested that the pattern of days off school/stayed in because of asthma differed between the two groups, favouring the treatment group. However, this was based on data from only 76 children and may have been overly influenced by data from one or two children.

This is the first study to test the effect of classical homeopathy in asthma and has the added strength of being pragmatic: homeopaths were free to practise in their usual way, combining homeopathic prescriptions with lifestyle suggestions and other advice. We believe it is important to test homeopathy in the form in which it is commonly practised rather than in a form specially modified for clinical trials. We also believe that alternative therapies should be tested under the conditions that are most promising of a positive result. This trial was designed with the input of experienced homeopaths for optimal conditions. In particular, we ensured that freedom of prescription was not curtailed in any way so that homeopaths could use any remedy and could change that remedy during the trial. We also believed that it was important to include more than one homeopath in the study, as our negative result might have been attributed to lack of competence of a single therapist. We chose to test the effect on children because, according to homeopathic belief, children are more likely to respond than adults. Most importantly, we included a long follow up period to give patients with this chronic disease the 
opportunity to respond to treatment. The study was designed to be relatively undemanding for patients in terms of completing questionnaires. This may have resulted in missing some transient changes in symptoms, but led to a high rate of retention in the trial. The values for CAQ for those who did not complete baseline CAQ is unlikely to change the conclusion.

The main weaknesses of the study were the limitations of the primary outcome measure and the mildness of the children's asthma. The CAQ has the benefit of asking questions that are relevant to patients' experience of how asthma affects their quality of life and has been validated. However, it has the disadvantage that the same questions are not applicable to different age groups and the results are therefore difficult to combine. A scale for quality of life in children that was published later is applicable to a wider range of ages. ${ }^{14}$ There is no evidence from the different subgroups of different ages (table 2) of any trend suggesting that a larger trial would have shown an effect, but the scales may be insensitive to change. The children had severity scores of about 11 , which is similar to the scores described as "mild" in a validation study. This presumably reflects the degree of control of asthma that can be achieved by modern medications judiciously applied. Children with severe asthma were excluded at the request of the research ethics committee. The result may have been different in more severely affected children (or, indeed, with different forms of homeopathy). The children included in the study reflected the primary care population who are regarded as having mild or moderate "asthma" and may have included some children with other respiratory problems including the hyperventilation syndrome. This does not weaken the study since homeopaths consider the history of the individual patient rather than the conventional clinical diagnosis.

Other researchers may wish to repeat the study in a different sample. Our study design would have been improved by conducting a pilot study on which to base a sample size calculation, by stratifying children additionally by age, and by choosing outcome measures (or modifying those used) to be more sensitive to change.

There are no previous studies of individualised classical homeopathy with which to compare this study. A review of 32 published studies of individualised homeopathy for all conditions found that the overall clinical outcome was superior to that with placebo. ${ }^{7}$ However, when the analysis was restricted to the methodologically best trials, homeopathic remedies did not differ from placebo ${ }^{15}$; this study supports the latter hypothesis.

\section{ACKNOWLEDGEMENTS}

The authors thank the homeopaths Rita Tremain, Mike Bridger and Marietta Honig; Dr Charlotte Paterson; the research nurses Delyth Swann and Ann Greenwood for their help with the study.

\section{Authors' affiliations}

A White, E Ernst, Complementary Medicine, Peninsula Medical School, Universities of Exeter and Plymouth, Exeter EX2 4NT, UK

P Slade, Irnham Lodge Surgery, Townsend Road, Minehead. Somerset, UK

C Hunt, Harley House Surgery, Irnham Road, Minehead, Somerset, UK A Hart, Postgraduate School of Medicine and Health, University of

Central Lancashire, Preston, Lancashire, UK

The study was coordinated by the Department of Complementary Medicine, School of Sport and Health Sciences, University of Exeter, UK.

The trial was planned and conducted by $\mathrm{AW}, \mathrm{PS}, \mathrm{CH}$, and $\mathrm{EE}$. $\mathrm{AH}$ was responsible for statistical analysis of the data. All authors contributed to the final version of the paper.

Funding: The Prince of Wales's Foundation for Integrated Health, London provided a grant for the trial; Ainsworth's Pharmacy, London funded the remedies; and GlaxoSmithKline funded the CAQ questionnaire booklets.

Conflict of interest: none.

\section{REFERENCES}

1 Brown V, Ennis M. Flow-cytometric analysis of basophil activation: inhibition by histamine at conventional and homeopathic concentrations. Inflamm Res 2001;50(Suppl 2):S47-8.

2 Ernst E. Use of complementary therapies in childhood asthma. Pediatr Asthma Allergy Immunol 1998;21:29-32.

3 Linde K, Jobst KA. Homoeopathy for chronic asthma (Cochrane Review). In: The Cochrane Library. Issue 2. Oxford: Update Software, 2000.

4 Freitas LAS, Goldenstein E, Sanna OM. The indirect doctor-patient relationship and the homeopathic treatment of asthma in children. Revisto Homeopatia 1995:60:26-31.

5 Matusiewicz R. Engystol $\mathrm{N}$ bei Bronchialasthma unter kortikoidabhängiger Therapie. Biologische Medn 1995;24:242-6.

6 Reilly D, Taylor M, Beattie NGM, et al. Is evidence for homoeopathy reproducible? Lancet 1994;344:1601-6.

7 Linde K, Clausius N, Ramirez G, et al. Are the clinical effects of homeopathy placebo effects? A meta-analysis of placebo-controlled trials. Lancet 1997;350:834-43.

8 Christie MJ, French DJ, Sowden AJ, et al. Development of child-centred disease-specific questionnaires for living with asthma. Psychosom Med 1993;55:541-8.

9 French DJ, Christie M, Sowden AJ. The reproducibility of the childhood asthma questionnaires: measures of quality of life for children with asthma aged 4-16 years. Qual Life Res 1994;3:215-24.

10 French DJ, Christie M. Manual for the childhood asthma questionnaires. London: Allen and Hanburys, 1995.

11 Steen N, Hutchinson A, McColl E, et al. Development of a symptom based outcome measure for asthma. BM 1994;309:1065-8.

12 Lahdensuo A. Randomised comparison of guided self management and traditional treatment of asthma over one year. BM 1996;312:748-52.

13 Dantas F, Rampes H. Do homeopathic medicines provoke adverse effects? A systematic review. Br Homeopath J 2000;89(Suppl 1):S35-8.

14 Juniper EE, Guyatt GH, Feeny DH, et al. Measuring quality of life in children with asthma. Qual Life Res 1996;5:35-46

15 Linde K, Melchart D. Randomised controlled trials of individualized homeopathy: a state-of-the art review. J Altern Complement Med 1998;4:371-88. 